\title{
Analyzing Environmental of the Rural Women Cooperatives and their Share in the Agricultural Production in Tehran Province through SWOT Method
}

\author{
Masoumeh Arfaee* \\ Department of Agricultural, Ashtian Branch, Islamic Azad University, Ashtian, Iran \\ Email: M.Arfaee@gmail.com; Tell: 0098-9123381546 \\ Sara Rezaei \\ Vice-presidency for strategic planning and supervision, Tehran, Iran \\ Email: Sara_rezaei24@yahoo.com \\ Azita Zand \\ Department of Agricultural, Islamshahr Branch, Islamic Azad University, Islamshahr, Iran \\ Email: Azitazand@yahoo.com
}

\section{Doi:10.5901/mjss.2015.v6n3s2p518}

\begin{abstract}
The present study aimed to analyze the environmental of the rural Women cooperatives and their share in the agricultural production in Tehran province through SWOT method. The applied research method was descriptive - correlational. The population of the study was 7 units of rural women's cooperatives in Tehran province. Furthermore, the sampling procedure used in this research study was satisfied random sampling $(n=1631)$. The used questionnaire was distributed among the rural women cooperatives in Tehran Province in two levels of managers and staff members. The results of S.W.O.T revealed that the most appropriate adaptive strategy was to develop the opportunity and possibility for staff members to educate in different levels; the most appropriate offensive strategy was to employ skillful human sources; the most appropriate defensive strategy was to increase the motivation of staff members in the way of attracting their partnership in related activities nor control activities; and the most appropriate contingency strategy was to decrease the number of staff members through new technologies. These strategies might play the core role in increasing revenue and the share in the agricultural production at rural women cooperatives in Tehran province.
\end{abstract}

Keywords: Rural women's cooperatives, Agricultural production, S.W.O.T Analysis (strengths, weaknesses, opportunities, threats).

\section{Introduction}

In Iran given the development of economic evolutions, policy making and also the delivering the economic and productive activities to non-governmental sectors, access of women to land, agricultural inputs and loan within rural cooperative Co. has recently increased. As a result, it has become possible to supply agricultural inputs, selling products, and processing crops with more productivity, integrate human resources, and to employ staff more easily (Golkar,2008). Thus, one of the most suitable methods of analyzing strategic management is the SWOT (strengths, weaknesses, opportunities and threats) technique that can be used even under inappropriate conditions (Ahmadi,2009). Under critical conditions, the best tool is offered to manage the intended unit in the critical and difficult conditions so that the most appropriate decision would be made.

Walters \& Rainbird (2007) in their study reported that increasing innovation of cooperatives requires a combination of of elements including: product innovation management and innovation management at the structure of communication network. This research benefits from a model to facilitate the effectiveness of innovative cooperatives.

Premchander and Pranmeela (2004) also carried out another study titled as "developing trade of rural women cooperative in Thailand" whose results uncovered that recognizing environmental factors and improving innovation potentials in rural women cooperative might lead to an increase in the number of dependant women to self-sufficiency, establishment of small and medium size businesses, and also encouragement of entrepreneurship.

Moreover, in the research study by Ahmadi (2009), the effective factors on membership of farmers at cooperatives 
at Fars province was studied and resuit was finally understood that there is a significant relationship between individual properties, economic properties and social respect of respondents with the membership in cooperative. Similarly, Mohammadi Rad (2007) studied the effective factors on success of cooperative companies in Tehran province using the questionnaire of supreme educated managers and finally concluded that the factor of capital plays a key role for success of cooperative companies' investment on rural plans. In a similar vein, Ghebremichael (2013) also reported that women are capable to make ends meet in their lives and are largely satisfied from the services they receive from the cooperatives. He further maintains that women mostly feel happy due to their fiscal independence and their accepting of identity by society.

Given these points, the current paper aims to make an environmental analysis of the rural Women cooperatives and their share in the agricultural production in Tehran province through SWOT method. Besides, the study specifically addresses the followings: 1- identifying individual and environmental factors in two levels of members and managers and staffs of rural women cooperatives on agricultural production 2- environmental analysis of individual factors and economic environmental features using SWOT.

\section{Material and Method}

The research method of the present study was of descriptive - correlational type. Its population was 7 units of rural women's cooperatives located in Tehran province and the sampling procedure utilized in the research was satisfied random sampling ( $\mathrm{n}=1631)$. The used questionnaire was distributed among the rural women cooperatives of Tehran Province in two levels of managers and staff members.

Furthermore, to perform theoretical and qualitative studies effectively and appropriately, documentary method and in order to perform quantitative stage, the field method was used. In field method descriptive statistical test, inferential test and SWOT test through SPSS software were run. SWOT technique is usually taken as a tool for recognizing the threats and opportunities in a foreign environment system and also recognizing its internal weak and strong points for the purpose of evaluating its conditions and using appropriate strategies to control and direct the system efficiently. SWOT is, in fact, a combination of some techniques dealing with domestic factors and foreign environment of organization. In short, it is stated that such technique analyzes status and strategy (Bowman, 2006).

\section{Results}

\subsection{Descriptive Results}

\subsubsection{Prioritizing effective forms for individual properties of employees and members of cooperative}

Given the comments provided by respondents regarding the independent variables, the most important individual properties of employees and members of cooperative such as continuous commitment and interests which were assessed based on a Likert scale were as follows: making ends meet (meeting life expenses), satisfaction of observing justice among employees of cooperative, relationship between satisfaction of job and education. Besides, the 3 final priorities are: interest in learning, offering new innovations for job description, interest in attending extra hour plans and interest in other members of cooperative.

Table 1) Prioritizing effective forms, individual properties of employees and members of cooperative

\begin{tabular}{|l|c|c|c|}
\hline Factor & Average & Standard deviation & Coefficient of Variation \\
\hline Interest in your cooperative & 3.81 & 1.08 & 0.283 \\
\hline Interest in cooperation among other cooperatives under this condition & 3.26 & 0.88 & 0.269 \\
\hline Interest in job description of cooperative & 3.58 & 1.12 & 0.312 \\
\hline Interest to other members of cooperative & 3.45 & 0.74 & 0.214 \\
\hline Mutual interest to other members and managers & 3.44 & 0.91 & 0.264 \\
\hline Respect to current rules and regulations of cooperative & 3.81 & 1.09 & 0.286 \\
\hline Satisfaction of legislation in cooperative & 3.40 & 1.07 & 0.314 \\
\hline Satisfaction of executing law in cooperative & 3.50 & 1 & 0.285 \\
\hline Satisfaction of observing justice among employees of cooperative & 3.41 & 1.25 & 0.366 \\
\hline Satisfaction of income & 3.03 & 0.91 & 0.300 \\
\hline Meeting life expenses & 3.04 & 1.17 & 0.384 \\
\hline
\end{tabular}




\subsection{Prioritizing Effective Forms of Individual Properties of Cooperative Managers}

Based on comments of respondents as with other independent variables, some of the most important individual properties of cooperative managers such as norm commitment, importance of employees, etc. that were assessed by a Likert scale revealed that the three most basic priorities were: Effective relationship with applicable organizations (Ministry of Cooperative and Agricultural Affairs), attending at educational sessions and workshops in charge of governmental organizations, and interest in extra hour plans. Furthermore, final priorities were: interest in cooperative itself, attempt for increasing teamwork among employees and members, relationship with other cooperative managers, and being informed of new innovations

Table 2: Priorities of effective form related to individual properties of cooperative managers:

\begin{tabular}{|l|c|c|c|}
\hline Factor & Average & Standard Deviation & Coefficient of Variation \\
\hline Interest in your cooperative & 4.11 & 0.79 & 0.192 \\
\hline Interest in cooperation among other cooperatives under this condition & 3.73 & 1.02 & 0.273 \\
\hline Interest in job description of cooperative & 3.89 & 1.07 & 0.275 \\
\hline Interest to other members of cooperative & 3.88 & 1.06 & 0.274 \\
\hline Mutual interest to other members and managers & 3.77 & 1.19 & 0.315 \\
\hline Attempt for legislation of partnership & 3.83 & 1.18 & 0.308 \\
\hline Satisfaction of legislation in cooperative & 3.60 & 1.04 & 0.288 \\
\hline Satisfaction of executing law in cooperative & 3.60 & 1.12 & 0.311 \\
\hline Satisfaction of income & 3.75 & 1.21 & 0.322 \\
\hline Meeting life expenses & 3.56 & 0.98 & 0.275 \\
\hline Relationship of job with education & 4.06 & 1.12 & 0.276 \\
\hline Relationship of job with profession & 3.94 & 1.02 & 0.258 \\
\hline Access to modern managerial and agricultural knowledge through Internet & 3.81 & 0.92 & 0.241 \\
\hline Access to modern managerial and agricultural knowledge through study & 3.66 & 1.15 & 0.314 \\
\hline
\end{tabular}

\subsection{Inferential Results}

In examination of the independent variables, all the forms of each variable were included in the statistical test with index of independent variable (income of cooperative) and the obtained results were classified in the analysis tables of SWOT.

\section{Results of Analyzing SWOT Model}

\subsection{Strategic results with the highest rank:}

In this analysis the continuous commitment and individual characters of employees and members of cooperative were found to have the highest of strong point. Besides, education and individual characters of employees and members of cooperative revealed the highest of weak point. Additionally, being punctual (importance of time), individual characters of employees and members of cooperative had the highest of threat point. And finally, working hour- individual characters of employees and members of cooperative showed the highest of opportunity point in rural women cooperative of Tehran province

\subsection{Internal Factor Evaluation (IFE)}

4.2.1 Results of inferential analysis and type of relationship between independent variables and dependant variables (positive, significant and effective)

Table 3: Internal factor evaluation (Strong points)

\begin{tabular}{|c|l|c|c|c|}
\hline Row & Strong Point & Correlation Coefficient & Rank & Point \\
\hline S1 & Continuous commitment, individual characters of employees and members of cooperative & 0.930 & 1 & 3.59 \\
\hline S2 & Commitment to guarantee sale of cooperative in the previous year, economic characters of cooperative & 0.921 & 2 & 3.70 \\
\hline S3 & Circulation stock of cooperative in previous year, economic characters of cooperative & 0.900 & 3 & 3.81 \\
\hline S4 & Relationship with other cooperatives, individual characters of cooperative managers & 0.898 & 4 & 2.50 \\
\hline
\end{tabular}




\begin{tabular}{|c|c|c|c|c|}
\hline S5 & Emotional commitment, individual characters of cooperative managers & 0.895 & 5 & 2.55 \\
\hline S6 & Attention to interest of customers, individual characters of cooperative managers & 0.895 & 5 & 2.62 \\
\hline S7 & Number of marketers, economic characters of cooperative & 0.870 & 6 & 1.25 \\
\hline S8 & Immovable financial resources, economic characters of cooperative & 0.800 & 7 & 3.08 \\
\hline S9 & Method sale, economic characters of cooperative & 0.798 & 8 & 2.58 \\
\hline S10 & Continuous commitment, economic characters of cooperative & 0.784 & 9 & 3.95 \\
\hline S11 & Capital resources, economic characters of cooperative & 0.751 & 10 & 1.32 \\
\hline S12 & Income of cooperative in previous year, economic characters of cooperative & 0.750 & 11 & 2.60 \\
\hline S13 & Emotional intelligence, individual characters of employees and members of cooperative & 0.721 & 12 & 1.45 \\
\hline
\end{tabular}

\subsubsection{Results of inferential analysis and type of relationship with independent variables and dependant variables (positive, significant and weak)}

Table 4: Internal Factor Evaluation of domestic factors (weak points)

\begin{tabular}{|c|c|c|c|c|}
\hline Row & Weak Point & Correlation Coefficient & Rank & Point \\
\hline W1 & Education- individual characters of employees and members of cooperative & 0.096 & 1 & 2.13 \\
\hline W2 & behavior with diseases and pests- environmental characters of cooperative & 0.127 & 2 & 2.11 \\
\hline W3 & elementary capital of cooperative- economic characters of cooperative & 0.135 & 3 & 4.41 \\
\hline W4 & type of cooperative- environmental characters of cooperative & 0.152 & 4 & 3.08 \\
\hline W5 & supplying agricultural inputs- environmental characters of cooperative & 0.157 & 5 & 4.42 \\
\hline W6 & geographical location of cooperative- environmental characters of cooperative & 0.164 & 6 & 4.52 \\
\hline W7 & ???- environmental characters of cooperative & 0.210 & 7 & 2.87 \\
\hline W8 & marital status-- individual characters of employees and members of cooperative & 0.215 & 8 & 2.54 \\
\hline W9 & supplying fuel- environmental characters of cooperative & 0.223 & 9 & 1.84 \\
\hline W10 & Education- individual characters of cooperative managers & 0.258 & 10 & 2.67 \\
\hline W11 & work hour- individual characters of cooperative managers & 0.322 & 11 & 1.02 \\
\hline W12 & Age- individual characters of cooperative managers & 0.347 & 12 & 4.02 \\
\hline W13 & ownership of real estate- environmental characters of cooperative & 0.351 & 13 & 3.75 \\
\hline W14 & Record of membership- - individual characters of employees and members of cooperative & 0.363 & 14 & 2.58 \\
\hline W15 & Scope of duties- - individual characters of employees and members of cooperative & 0.365 & 15 & 3.15 \\
\hline
\end{tabular}

\subsubsection{Results of inferential analysis and type of relationship between independent variables with dependant variable} (Negative, significant and weak)

Table 5: Internal Factor Evaluation

\begin{tabular}{|c|c|c|c|c|}
\hline Row & Threat Point & Correlation Coefficient & Rank & Point \\
\hline $\mathrm{T} 1$ & Punctual (importance of time) individual characters of cooperative managers & -0.610 & 1 & 2.13 \\
\hline $\mathrm{T} 2$ & Service education, individual characters of employees and members of cooperative & -0.550 & 2 & 2.51 \\
\hline T3 & Number of members, characters of cooperative members & -0.343 & 3 & 2.11 \\
\hline T4 & Number of children, individual characters of cooperative managers & -0.228 & 4 & 4.41 \\
\hline T5 & Number of active trainers, economic characters of cooperative & -0.080 & 5 & 4.42 \\
\hline
\end{tabular}

\subsubsection{Results of inferential analysis and type of relationship between independent variables and dependant variable (negative, significant and medium)}

Table 6: Internal Factor Evaluation of foreign factors (opportunity point)

\begin{tabular}{|c|c|c|c|c|}
\hline Row & opportunity Point & Correlation Coefficient & Rank & Point \\
\hline 01 & Work hour, individual property of employees and members of cooperative & 0.687 & 1 & 2.13 \\
\hline $\mathrm{O} 2$ & Norm commitment, individual characters of cooperative managers & 0.650 & 2 & 2.11 \\
\hline 03 & Service record of managerial affairs, individual characters of cooperative managers & 0.642 & 3 & 4.41 \\
\hline 04 & Scope of duties of cooperative, environmental characters of cooperative & 0.636 & 4 & 4.42 \\
\hline 05 & Movable financial resources, economic characters of cooperative & 0.620 & 5 & 1.28 \\
\hline 06 & Using discount and tax exemptions, economic characters of cooperative & 0.580 & 6 & 2.32 \\
\hline 07 & Marketing status, economic characters of cooperative & 0.560 & 7 & 2.52 \\
\hline O8 & Number of warehouses, economic characters of cooperative & 0.520 & 8 & 1.14 \\
\hline 09 & Concluding contract with insurance, economic characters of cooperative & 0.480 & 9 & 4.32 \\
\hline 010 & Field of study, individual characters of cooperative managers & 0.458 & 10 & 2.16 \\
\hline 011 & Marital status, individual characters of cooperative managers & 0.458 & 10 & 3.81 \\
\hline 012 & Importance of employees, individual characters of cooperative managers & 0.455 & 11 & 2.57 \\
\hline 013 & Growth rate of capital, economic characters of cooperative & 0.420 & 12 & 3.44 \\
\hline
\end{tabular}




\section{Strategy Model \& Final Conclusion:}

SWOT matrix enables us to have 4 choices or different strategies. However, in practice, some strategies are integrated or executed simultaneously. Based on the status of system and strategy model of Robinson Pierce, 4 classes of strategies with different degree of reaction were prepared.

Table 7: Strategy model and final matrix of SWOT based on Robinson Pierce model

\begin{tabular}{|c|c|}
\hline \multicolumn{2}{|c|}{ Domestic Environment } \\
\hline Weak Point & Strong Point \\
\hline $\begin{array}{l}\text { WO (minimum-maximum) } \\
\text { 1) Opportunity of continuing education at different levels for } \\
\text { cooperative employees } \\
\text { 2) Recruitment for single employees } \\
\text { 3) Increasing elementary capital of cooperative until final } \\
\text { possible level through absorbing foreign and people } \\
\text { investment } \\
\text { 4) Buying property and building of cooperative and its } \\
\text { registration on official basis } \\
\text { 5) Appointment of old age, experienced and educated } \\
\text { managers in the field of management and duties of } \\
\text { cooperative } \\
\text { 6) Supplying agricultural inputs, fuel of cooperative, behaving } \\
\text { with diseases and pests from view point of government and } \\
\text { private sector under ordinary and critical condition } \\
\text { 7) Nearness of cooperative to city centers by using step by } \\
\text { step purchase method }\end{array}$ & $\begin{array}{l}\text { SO (maximum-maximum) } \\
\text { 1) Recruitment of skilful human workforce at cooperative } \\
\text { 2) Increasing mutual trust of members toward each other by different solutions of } \\
\text { human resource management } \\
\text { 3) Offering financial statement regularly at the end of year } \\
\text { 4) Enacting continuous laws related to life, salary and wage, welfare of } \\
\text { employees } \\
\text { 5) Following up enacted rules and support of their execution } \\
\text { 6) Appointment of married managers with record of managerial jobs and related } \\
\text { education } \\
\text { 7) Increasing work hour of cooperative even during holidays } \\
\text { 8) Selecting legal scope of duties with highest rate of sale } \\
\text { 9) Increasing movable finance } \\
\text { 10) Increasing capital growth rate by suitable methods and strategies and } \\
\text { observing level of sale and circulation stock of cooperative on capital growth } \\
\text { 11) Following up opportunities by using discount and financial exemptions } \\
\text { 12) Benefiting full capacities of market for sale } \\
\text { 13) Increasing recruitment of sale and marketing employees in the field of } \\
\text { advertisement and market strategies } \\
\text { 14) Attention and application of customer oriented theories in the field of } \\
\text { advertisement and market strategies } \\
\text { 15) Increasing number of warehouses and creating investment opportunity for } \\
\text { purchase and construction of new warehouses } \\
\text { 16) Concluding suitable contracts in all fields with insurance for prevention and } \\
\text { compensation under critical condition }\end{array}$ \\
\hline
\end{tabular}

WT (minimum-minimum)

1) Increasing motivation of employees and members of cooperative through their partnership at related activities rather than controlling them

2) Continuous opportunity for partnership at inner investment at cooperative

3) Appointment of skilful managers based on concentration on employees

4) Reducing number of members with suitable planning for application of

modern technologies and nearness of cooperative to city centers

5) Prevention of wasting time of employees and members at service

education courses

6) Increasing volunteer courses of employees
ST (maximum-minimum)
1) Reducing number of employees and members through application of modern technologies
2) Appointment of managers with less number of children 3) Recruitment of few number of trainers with maximum skill and ability for allocating higher time to employees of cooperative 4) Reducing time of service education and concentration on recruitment of skilful employees
5) Reducing sensitivity and managerial difficulties in relation to activity time of employees and control their entrance and exit

\section{Conclusion and Recommendations}

The most important individual properties of employees and members of cooperative were found to be as follows: continuous commitment, interests that are evaluated based on a Likert scale. Furthermore, the most important individual properties of cooperative managers were: norm commitment, importance of employees, etc. that, like the previous case, are evaluated by a Likert scale. In this analysis, the continuous commitment, individual characters of employees and members of cooperative showed the highest of strong point. Based on status of system and strategy model of Robinson Pierce, 4 classes of strategies with different degree of reaction were prepared. Recruitment of skilful human workforce at cooperative was a strong point and Opportunity of continuing education at different levels for cooperative employees were found to be a weak point in cooperatives.

Studying comments and recent studies by Walters and Rainbird (2007) and Ahmadi (2009) showed that there is an effective relationship between applicable organizations and prioritizing individual properties of cooperative managers. In addition, the study by Premchander and Prameela (2004) showed that increasing mutual trust of family members using different strategies of human resource management is among the strong points of rural women cooperatives. Given that in the SWOT analysis, the appropriate strategies for rural women cooperative in compliance with strategic points of 
cooperative were extracted, the following points need to be mentioned:

1) Renewal of process management structure and mechanism of work method in compliance with requirements of organization, ideology, motivation and condition of rural women

2) Increasing teamwork at rural cooperative and Ministry of Cooperative, Labor and Social Welfare

3) Recruitment and application of skilful forces, qualified counselors and benefiting training course

4) Increasing independence through attracting small investment and NGO

5) Complete support of government from rural women NGO, planning, policy making in the way of allocating budget, agricultural inputs and etc to rural women cooperatives

\section{Acknowledgment}

This research was done with financial assisstance of Islamic Azad University, Ashtian branch. The authors deeply express their gratitude to the related officials for providing the required conditions and opportunities to carry out the research.

\section{References}

Ahmadi, Mohammad Taghi. (2009). Studying effective Factors in Membership the farmers in rural production cooperatives on Pattern in the form of indoctrination of innovations Diffusion, MSc Thesis of Agricultural Education and Extension, Tarbiyat Modares University.

Bowman,E .(2006).The Basics Of S.W.O.T Analysis For Cooperatives, www.nwcdc.coop.

Ghebremichael,Berhane.(2013). The role of cooperatives in empowering women. Journal of Business management \& Social science research(JBM\&SSR).Vol2, No.5, May 2013, 51-54.

Golkar, Koroush. (2008). Town Planning in Practice: Modeling for Multilevel Guidance and control in urban design, Abadi Journal, no.56.

Mohammadi Rad, Forazandeh. (2007). Studying effective Factors in success of rural cooperatives in Tehran Province, MSc Thesis of Public management, Tehran University.

Premchander, S., and Prameela, V. (2004). Promoting rural women's cooperative businesses in Thailand. A training kit. Part 2, RAP publication 2004, FAO.

Wang, L. (2012). Success cases and good practices in forest farmer cooperative organization in China, Food and Agricultural Organization of United Nations, Rome, Italy.

Walters, D., and Rainbird, M. (2007). Strategic Operations Management: a Value Chain Approach, Palgrave.Basingstoke, UK. 